\title{
Addition of vildagliptin to insulin improves glycaemic control in type 2 diabetes
}

\author{
V. Fonseca • A. Schweizer - D. Albrecht • M. A. Baron • \\ I. Chang $\cdot$ S. Dejager
}

Received: 25 October 2006 / Accepted: 30 January 2007 / Published online: 27 March 2007

(C) Springer-Verlag 2007

\begin{abstract}
Aims/hypothesis Type 2 diabetes is difficult to manage in patients with a long history of disease requiring insulin therapy. Moreover, addition of most currently available oral antidiabetic agents increases the risk of hypoglycaemia. Vildagliptin is a dipeptidyl peptidase-IV inhibitor, which improves glycaemic control by increasing pancreatic beta cell responsiveness to glucose and suppressing inappropriate glucagon secretion. This study assessed the efficacy and tolerability of vildagliptin added to insulin therapy in patients with type 2 diabetes.

Materials and methods This was a multicentre, 24-week, double-blind, randomised, placebo-controlled, parallelgroup study in patients with type 2 diabetes that was inadequately controlled $\left(\mathrm{HbA}_{1 \mathrm{c}}=7.5-11 \%\right)$ by insulin. Patients received vildagliptin ( $n=144 ; 50 \mathrm{mg}$ twice daily) or placebo $(n=152)$ while continuing insulin therapy.
\end{abstract}

Electronic supplementary material The online version of this article (doi:10.1007/s00125-007-0633-0) contains a complete list of investigators which is available to authorised users.

V. Fonseca $(\square)$

Endocrinology Department,

Tulane University Health Sciences Center,

1430 Tulane Ave. \#SL53,

New Orleans, LA 70112, USA

e-mail: vfonseca@tulane.edu

A. Schweizer · D. Albrecht

Novartis Pharma AG,

Basel, Switzerland

M. A. Baron - I. Chang - S. Dejager

Novartis Pharmaceuticals Corporation,

E. Hanover, NJ, USA
Results Baseline $\mathrm{HbA}_{1 \mathrm{c}}$ averaged $8.4 \pm 0.1 \%$ in both groups. The adjusted mean change from baseline to endpoint $(\mathrm{AM} \Delta)$ in $\mathrm{HbA}_{1 \mathrm{c}}$ was $-0.5 \pm 0.1 \%$ and $-0.2 \pm$ $0.1 \%$ in patients receiving vildagliptin or placebo, respectively, with a significant between-treatment difference $(p=0.01)$. In patients aged $\geq 65$ years, the $\mathrm{AM} \Delta \mathrm{HbA}_{1 \mathrm{c}}$ was $-0.7 \pm 0.1 \%$ in the vildagliptin group vs $-0.1 \pm 0.1 \%$ in the placebo group $(p<0.001)$. The incidence of adverse events was similar in the vildagliptin $(81.3 \%)$ and placebo $(82.9 \%)$ groups. However, hypoglycaemic events were less common $(p<0.001)$ and less severe $(p<0.05)$ in patients receiving vildagliptin than in those receiving placebo.

Conclusions/interpretation Vildagliptin decreases $\mathrm{HbA}_{1 \mathrm{c}}$ in patients whose type 2 diabetes is poorly controlled with high doses of insulin. Addition of vildagliptin to insulin therapy is also associated with reduced confirmed and severe hypoglycaemia. ClinicalTrials.gov ID no.: NCT 00099931.

Keywords Clinical diabetes · DPP-4 - Glycaemic control . $\mathrm{HbA}_{1 \mathrm{c}} \cdot$ Hypoglycaemia $\cdot$ Insulin therapy .

Oral pharmacological agents $\cdot$ Vildagliptin
Abbreviations
$\mathrm{AM} \Delta$ adjusted mean change from baseline to endpoint
BARC Bioanalytical Research Corporation
DPP-4 dipeptidyl peptidase-IV
FPG fasting plasma glucose
LOCF last observation carried forward
NGSP National Glycohemoglobin Standardization Program
SMBG self-monitored blood glucose 


\section{Introduction}

Vildagliptin is a potent and selective inhibitor of dipeptidyl peptidase-IV (DPP-4) that improves glycaemic control in patients with type 2 diabetes, primarily by enhancing pancreatic islet function. Thus vildagliptin has been shown both to increase beta cell responsiveness to glucose [1] and to suppress the inappropriate glucagon secretion seen in patients with type 2 diabetes [2]. Vildagliptin reduces $\mathrm{HbA}_{1 \mathrm{c}}$ when given as monotherapy [3, 4] or in combination with metformin [5], but its efficacy is unknown in patients who have a long history of disease requiring insulin therapy.

This is particularly important because as diabetes progresses, its management becomes increasingly difficult. Patients often have multiple comorbidities requiring pharmacological treatment. Due to contraindications, this can limit therapeutic options and may also lead to suboptimal patient compliance. Hypoglycaemia may become a limiting factor in the treatment of patients with advanced disease [6]. Moreover, insulin-treated patients with type 2 diabetes are often profoundly insulin-resistant and require high doses, which can exacerbate weight gain.

The present study was undertaken, therefore, to assess the efficacy and tolerability of vildagliptin $(50 \mathrm{mg}$ twice daily) vs placebo in patients with type 2 diabetes who continued insulin treatment.

\section{Subjects and methods}

Overall study design and patient population This was a 24week, randomised, double-blind, placebo-controlled, parallel-group study to assess the efficacy and tolerability of vildagliptin (50 mg twice daily) in 296 type 2 diabetic patients whose diabetes was inadequately controlled with insulin monotherapy $\left(\mathrm{HbA}_{1 \mathrm{c}} 7.5-11.0 \%\right)$. The study was conducted in 68 centres in the following countries: Germany (ten), Finland (five), Spain (four) and the USA (49). Potential participants attended a screening visit (Week -4), during which inclusion/exclusion criteria were assessed. Eligible patients were randomised at Week 0 to receive vildagliptin (50 $\mathrm{mg}$ twice daily) or placebo, subsequently attending five additional visits (Weeks 4, 8, 12, 16 and 24). For the patient disposition, see Fig. 1.

To be eligible, patients had to have received only injectable insulin for at least 3 months, at a dose of at least $30 \mathrm{U} /$ day for a minimum of 4 weeks prior to enrolment. Male and female patients (non-fertile or of childbearing potential using a medically approved birth control method) were eligible upon fulfilment of the following conditions: aged 18-80 years, inclusive; $\mathrm{HbA}_{1 \mathrm{c}}$ 7.5-11.0\%; fasting plasma glucose (FPG) $<15 \mathrm{mmol} / \mathrm{l}$; and BMI $22-45 \mathrm{~kg} / \mathrm{m}^{2}$, inclusive. The diagnosis of patients with type 2 diabetes was based on the

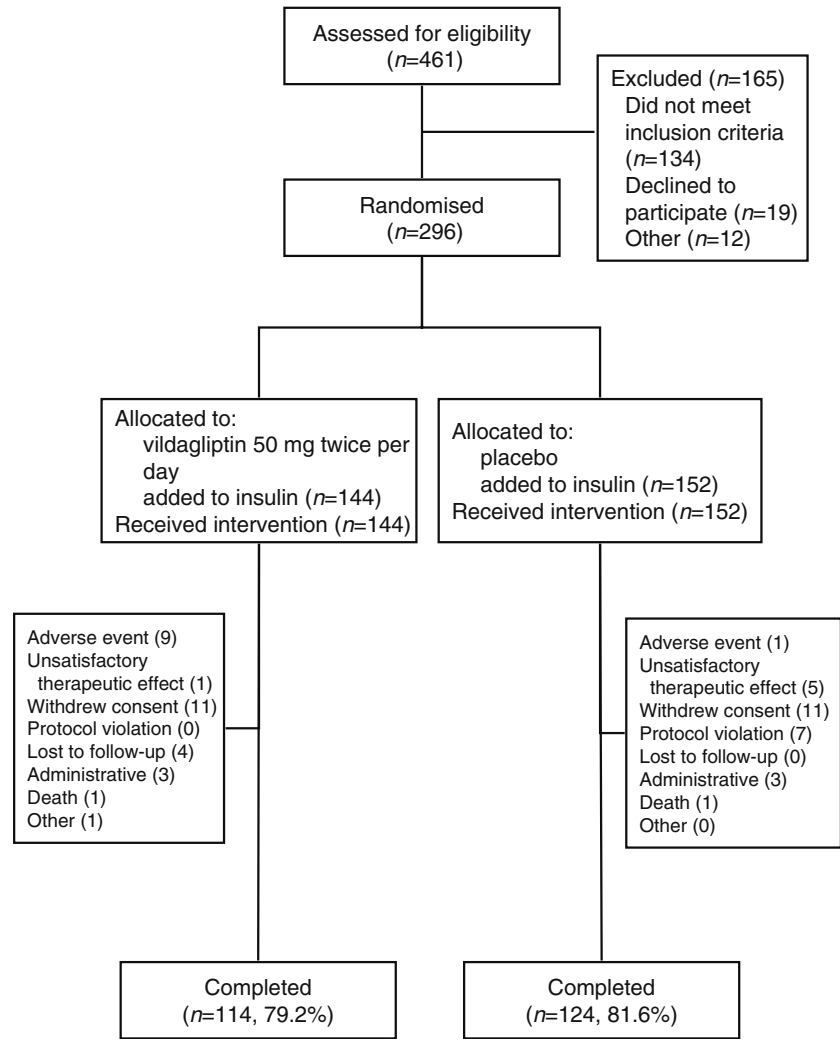

Fig. 1 Patient disposition. The primary outcome $\left(\mathrm{AM} \Delta \mathrm{HbA}_{1 \mathrm{c}}\right)$ was analysed in 140 of 144 patients receiving vildagliptin $(50 \mathrm{mg}$ twice daily) and in 149 of 152 patients receiving placebo. Four and three patients receiving vildagliptin or placebo, respectively, had no valid post-randomisation or baseline $\mathrm{HbA}_{1 \mathrm{c}}$ value

investigator's diagnosis and on the patient's medical record. Patients with type 1 diabetes, diabetes resulting from pancreatic injury or with secondary forms of diabetes (e.g. Cushing's syndrome or acromegaly) were excluded, as were those with acute metabolic diabetic complications within the past 6 months, serious cardiac conditions or clinically significant liver disease. Any of the following laboratory abnormalities precluded participation: alanine transaminase or aspartate transaminase $>3$ times the upper limit of normal; direct bilirubin $>1.3$ times the upper limit of normal; serum creatinine $>220 \mu \mathrm{mol} / \mathrm{l}$; fasting triacylgylcerol $>7.9 \mathrm{mmol} / \mathrm{l}$.

During the study, patients were to be discontinued due to 'unsatisfactory therapeutic effect' if during the study they experienced an FPG $>15 \mathrm{mmol} / \mathrm{l}$ confirmed by a repeat measurement or symptoms of worsening hyperglycaemia (i.e. polyuria, polydipsia, weight loss), in the absence of intercurrent illness or other potential event causing deterioration of glucose control. Discontinuation due to 'unsatisfactory therapeutic effect' was also possible solely on the basis of the investigator's judgment and without the affected patient meeting the above-mentioned, pre-specified criteria. 
Study assessments The primary efficacy parameter was the change from baseline to Week 24 or endpoint in $\mathrm{HbA}_{1 \mathrm{c}}$ in the intent-to-treat population with last observation carried forward (LOCF) for patients with no measurement for Week 24. Secondary efficacy parameters included FPG, mean daily insulin dose, mean daily number of insulin injections, fasting lipid parameters (triacylglycerol, total cholesterol, HDL, calculated LDL, VLDL and non-HDLcholesterol) and body weight. $\mathrm{HbA}_{1 \mathrm{c}}, \mathrm{FPG}$, insulin dose regimen and body weight were recorded at each study visit. Lipid profiles were assessed at Weeks -4, 0, 12 and 24.

Although insulin dose adjustments were allowed during the study, patients were asked to use the same type of insulin throughout and, if possible, to maintain their daily insulin regimen. Investigators were allowed to decrease a patient's insulin dose according to their clinical judgement in the event of severe or repeated hypoglycaemic episodes. Upward dose adjustments were allowed as clinically indicated, but were recommended to remain within $25 \%$ of the baseline insulin dose.

All adverse events were recorded and assessed by the investigator as to severity and possible relationship to study medication. Vital signs were recorded at each study visit; safety laboratory assessments were made at Weeks $-4,0,4$, 12 and 24; ECGs were performed at Weeks -4, 0, 12 and 24. Patients were given glucose monitoring devices with unlimited supplies and instructed on their use, with a view to performing routine self-monitored blood glucose (SMBG) measurements as instructed by the investigator. They were asked to record the measured values at any time hypoglycaemia was suspected and also prior to breakfast at least three times per week. Confirmed hypoglycaemia was defined as symptoms suggestive of low blood glucose confirmed by an SMBG measurement $<3.1 \mathrm{mmol} / \mathrm{l}$ plasma glucose equivalent. Severe hypoglycaemia was defined as any episode requiring the assistance of another party (with plasma glucose value $<3.1 \mathrm{mmol} / \mathrm{l}$, unless the severity of the event precluded glucose determination).

All assessments were made by central laboratories. $\mathrm{HbA}_{1 \mathrm{c}}$ was quantified by HPLC, with reference to a Diabetes Control and Complications Trial standard, at a National Glycohemoglobin Standardization Program (NGSP) level 1 certified laboratory (Bioanalytical Research Corporation [BARC]-EU, Ghent, Belgium; or Covance-US, Indianapolis, IN, USA) or at an NGSP network laboratory (Diabetes Diagnostic Laboratory, Columbia, MO, USA). All other laboratory assessments were made by BARC-US (Lake Success, NY, USA) or BARC-EU. Assays were performed with standardised and validated procedures according to good laboratory practice.

Statistical analysis The primary efficacy variable was change from baseline $\mathrm{HbA}_{1 \mathrm{c}}$ at the end of the 24-week treatment. ANCOVA models with treatment and pre-defined pooled centre as classification variables and baseline measure as the covariate were used for all efficacy variables to test the hypothesis that vildagliptin ( $50 \mathrm{mg}$ twice daily) is superior to placebo. For fasting lipids, the per cent change from baseline was the unit of analysis for ANCOVA. Statistical significance was determined on the basis of twosided $p$ values from the ANCOVA models. Pre-specified subanalyses were performed to examine efficacy and tolerability in patients $<65$ and $\geq 65$ years of age, and to assess efficacy on the basis of initial BMI $\left(<\right.$ or $\left.\geq 30 \mathrm{~kg} / \mathrm{m}^{2}\right)$.

Ethics and good clinical practice All participants provided written informed consent. The protocol was approved by the independent ethics committee/institutional review board at each study site and the study was conducted using Good Clinical Practice in accordance with the Declaration of Helsinki.

\section{Results}

Patients studied In total, 296 patients were randomised and 290 patients were included in the intent-to-treat population comprising all patients who received at least one dose of study medication and for whom at least one post-baseline $\mathrm{HbA}_{1 \mathrm{c}}$ result was obtained. Table 1 shows the demographic and baseline metabolic characteristics of the randomised population. The treatment groups were well balanced, with mean $\mathrm{HbA}_{1 \mathrm{c}}$ of $8.4 \%$ in both groups. Participants were predominantly white and obese (one in three being severely obese, with a BMI $>35 \mathrm{~kg} / \mathrm{m}^{2}$ ), with a mean age of 59.2 years, disease duration of 14.7 years and duration of insulin use of approximately 6 years. The mean insulin dose in the combined cohort was $82 \mathrm{U} /$ day, administered on average by three injections per day. About one-third of the patients in both groups were using insulin glargine and almost half were using a short-acting insulin (aspart or lispro) as part of their daily regimen; the remainder were using various combinations of NPH and regular insulin. In addition, $49 \%$ of all participants were receiving five or more concomitant medications for associated comorbidities. More than $30 \%$ of participants in both treatment groups were $\geq 65$ years of age. Table 1 also summarises the demographic and baseline characteristics of the subgroup of patients aged $<65$ years and $\geq 65$ years. As expected, the older subgroup (mean age 71 years) had a longer disease history ( $>18$ years) and longer use of insulin ( $>7$ years), but had baseline glycaemic control identical to that of the younger subgroup. The older patients also had a somewhat lower BMI, a lower mean daily insulin dose (66 U/day) and a similar mean number of injections. 
Table 1 Baseline characteristics of the randomised population

\begin{tabular}{|c|c|c|c|c|c|}
\hline & \multicolumn{3}{|l|}{ All randomised patients } & \multicolumn{2}{|c|}{ Subgroups based on age } \\
\hline & $\begin{array}{l}\text { Vildagliptin }^{\mathrm{a}}+\text { insulin } \\
(n=144)\end{array}$ & $\begin{array}{l}\text { Placebo }+ \text { insulin } \\
(n=152)\end{array}$ & $\begin{array}{l}\text { Total } \\
(n=296)\end{array}$ & $\begin{array}{l}\text { Subgroup aged } \\
<65 \text { years }(n=203)\end{array}$ & $\begin{array}{l}\text { Subgroup aged } \\
\geq 65 \text { years }(n=93)\end{array}$ \\
\hline Age (years) & $59.6 \pm 10.3$ & $58.9 \pm 10.8$ & $59.2 \pm 10.6$ & $53.9 \pm 8.0$ & $70.8 \pm 4.3$ \\
\hline Sex, $n(\%)$ male & $69(47.9)$ & $83(54.6)$ & $152(51.4)$ & $106(52.2)$ & $46(49.5)$ \\
\hline \multicolumn{6}{|l|}{ Race } \\
\hline Black & $22(15.3)$ & $17(11.2)$ & $39(13.2)$ & $29(14.3)$ & $10(10.8)$ \\
\hline White & $101(70.1)$ & $110(72.4)$ & $211(71.3)$ & $140(69.0)$ & $71(76.3)$ \\
\hline Hispanic or Latino & $17(11.8)$ & $22(14.5)$ & $39(13.2)$ & $29(14.3)$ & $10(10.8)$ \\
\hline All others & $4(2.8)$ & $3(2.0)$ & $7(2.3)$ & $5(2.4)$ & $2(2.1)$ \\
\hline Body mass index $\left(\mathrm{kg} / \mathrm{m}^{2}\right)$ & $33.3 \pm 5.2$ & $32.9 \pm 5.9$ & $33.1 \pm 5.6$ & $33.7 \pm 5.8$ & $31.6 \pm 5.0$ \\
\hline $\mathrm{HbA}_{1 \mathrm{c}}(\%)$ & $8.4 \pm 1.0$ & $8.4 \pm 1.1$ & $8.4 \pm 1.1$ & $8.4 \pm 1.1$ & $8.4 \pm 1.0$ \\
\hline $\begin{array}{l}\text { Fasting plasma glucose } \\
(\mathrm{mmol} / \mathrm{l})\end{array}$ & $9.3 \pm 3.1$ & $8.7 \pm 3.1$ & $9.0 \pm 3.1$ & $9.0 \pm 3.0$ & $9.0 \pm 3.2$ \\
\hline Disease duration (years) & $14.4 \pm 8.6$ & $14.9 \pm 8.4$ & $14.7 \pm 8.5$ & $13.1 \pm 7.6$ & $18.2 \pm 9.2$ \\
\hline $\begin{array}{l}\text { Duration of insulin use } \\
\text { (months) }\end{array}$ & $82.5 \pm 79.3$ & $67.9 \pm 65.2$ & $75.0 \pm 72.6$ & $70.2 \pm 67.0$ & $85.5 \pm 83.1$ \\
\hline Mean daily insulin dose (U) & $81.2 \pm 44.8$ & $81.9 \pm 49.4$ & $81.6 \pm 47.1$ & $88.7 \pm 50.9$ & $66.0 \pm 32.9$ \\
\hline $\begin{array}{l}\text { Mean daily number of } \\
\text { insulin injections }\end{array}$ & $2.8 \pm 1.2$ & $2.8 \pm 1.2$ & $2.8 \pm 1.2$ & $2.9 \pm 1.2$ & $2.7 \pm 1.2$ \\
\hline
\end{tabular}

Values are mean \pm SD or $n(\%)$

${ }^{a} 50 \mathrm{mg}$ twice daily

$H b A_{l c}$, FPG and insulin dose Figure 2 depicts the timecourse of mean $\mathrm{HbA}_{1 \mathrm{c}}$ in the intent-to-treat population. In patients for whom baseline and endpoint values were available, baseline $\mathrm{HbA}_{1 \mathrm{c}}$ averaged $8.4 \pm 0.1$ and $8.3 \pm 0.1 \%$ in patients receiving vildagliptin and placebo, respectively. In insulin-treated patients receiving vildagliptin (50 $\mathrm{mg}$ twice daily), the mean $\mathrm{HbA}_{1 \mathrm{c}}$ decreased progressively from Week 0 to Week 12 (mean change from baseline to Week $12-0.6 \pm$ $0.1 \%, n=118$ ) and remained essentially constant thereafter. In insulin-treated patients receiving placebo, $\mathrm{HbA}_{1 \mathrm{c}}$ decreased slightly during the first 4 weeks of study, then returned to baseline at Week 12; however, a modest decrease became apparent again by the end of the 24-week study. In patients receiving vildagliptin, the adjusted mean change from baseline to endpoint (AM $\Delta$ ) $\mathrm{HbA}_{1 \mathrm{c}}$ (with LOCF) was $-0.5 \pm 0.1 \%$. In patients receiving placebo, the $\mathrm{AM} \Delta \mathrm{HbA}_{1 \mathrm{c}}$ was $-0.2 \pm 0.1 \%$. The between-group difference in the AM $\Delta$ $\mathrm{HbA}_{1 \mathrm{c}}$ was $-0.3 \pm 0.1 \%(p=0.010)$.

In the $\geq 65$ years age group, a pre-planned subgroup analysis showed that baseline $\mathrm{HbA}_{1 \mathrm{c}}$ averaged $8.5 \%$ and $8.2 \%$ in those randomised to vildagliptin $(n=45)$ or placebo $(n=46)$, respectively. In these older patients, the $\mathrm{AM} \Delta \mathrm{HbA}_{1 \mathrm{c}}$ was $-0.7 \pm 0.1 \%$ during treatment with vildagliptin and $-0.1 \pm 0.1 \%$ during placebo administration. The between-group difference was $-0.6 \%(95 \% \mathrm{CI}$ -1.0 to $-0.3, p=0.001)$. In the subgroup of patients aged $<65$ years, baseline $\mathrm{HbA}_{1 \mathrm{c}}$ averaged 8.3 and $8.4 \%$ in those randomised to vildagliptin $(n=95)$ or placebo $(n=103)$, respectively. The AM $\Delta \mathrm{HbA}_{1 \mathrm{c}}$ was $-0.3 \pm 0.1 \%$ with vildagliptin and $-0.2 \pm 0.1 \%$ with placebo. The betweengroup difference was $-0.1 \%(95 \% \mathrm{CI}-0.4-0.1, p=0.361)$. Thus the efficacy of vildagliptin observed in the overall cohort was mainly driven by the effect seen in older patients. In contrast, BMI had little influence on the efficacy of vildagliptin (data not shown).

Baseline FPG averaged $9.4 \pm 0.3$ and $8.7 \pm 0.3 \mathrm{mmol} / \mathrm{l}$ in patients randomised to vildagliptin and placebo, respectively. During treatment with vildagliptin, FPG decreased promptly (mean change at Week $4-1.0 \pm 0.3 \mathrm{mmol} / \mathrm{l}, n=135$ ) and remained lower throughout the 24-week treatment (mean change from baseline at Week $24-0.8 \pm 0.3 \mathrm{mmol} / \mathrm{l}$, $n=115$ ). During administration of placebo, FPG was somewhat more erratic. The change from baseline to Weeks 4,12 and 24 averaged $0.3 \pm 0.3(n=144), 0.6 \pm 0.4(n=135)$ and $-0.2 \pm 0.4 \mathrm{mmol} / \mathrm{l}(n=126)$, respectively. However, the between-group difference in the AM $\Delta$ FPG from baseline to endpoint with LOCF $(-0.2 \pm 0.4 \mathrm{mmol} / \mathrm{l})$ was not statistically significant $(p=0.622)$. This was also the case when changes in FPG were analysed separately in patients $<65$ and $\geq 65$ years of age.

While patients were requested to keep their daily insulin regimens if possible, adjustments in insulin dose by the investigator were allowed throughout the study (see above, Study assessments). At baseline the mean daily insulin dose was $81.2 \pm 3.8$ and $81.3 \pm 3.9 \mathrm{U} /$ day in patients randomised to vildagliptin and placebo, respectively. The mean daily insulin dose increased modestly in vildagliptin-treated patients and to a somewhat greater degree in patients 


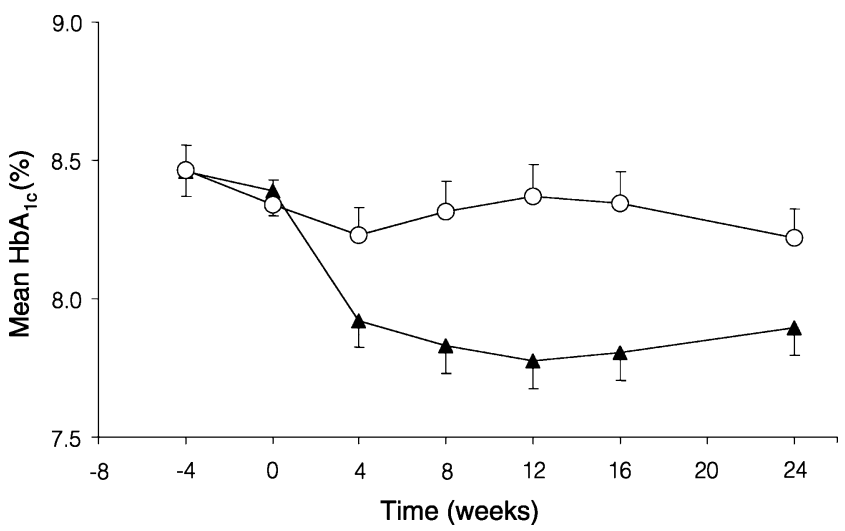

Fig. 2 Mean $\mathrm{HbA}_{1 \mathrm{c}}$ during 24-week treatment with vildagliptin (50 mg twice daily, $n=140)$ or placebo $(n=149)$ in patients with type 2 diabetes on continuing insulin therapy. Mean $\pm \mathrm{SE}$, intent-to-treat population. Closed triangles, vildagliptin + insulin; open circles, placebo + insulin

receiving placebo. The AM $\Delta$ insulin dose was $1.2 \pm 2.2$ in vildagliptin-treated patients and $4.1 \pm 2.1 \mathrm{U} /$ day in patients receiving placebo. The between-group difference in $\mathrm{AM} \Delta$ insulin dose was $-2.9 \pm 2.8 \mathrm{U} /$ day $(p=0.315)$. The mean number of insulin injections at baseline was $2.8 \pm 0.1$ (median=2 injections/day) in both groups of patients at baseline. At study endpoint, the mean number of daily insulin injections was $2.8 \pm 0.1$ (median $=$ two injections per day) in vildagliptin-treated patients and $2.9 \pm 0.1$ (median $=$ three injections per day) in patients receiving placebo. Thus, insulin therapy in both groups remained essentially stable. This was also true for the subgroup of patients aged $<65$ years. In this subgroup, the $\mathrm{AM} \Delta$ insulin dose was $-1.9 \pm 2.6 \mathrm{U} /$ day in patients receiving vildagliptin and $+2.4 \pm 2.4 \mathrm{U} /$ day in patients receiving placebo (between-group difference $-4.2 \pm 3.3 \mathrm{U} / \mathrm{day}, p=0.205$ ). In the subgroup of patients aged $\geq 65$ years, the $\mathrm{AM} \Delta$ daily insulin dose was $10.0 \pm 4.7 \mathrm{U} /$ day in patients receiving vildagliptin and $10.3 \pm 4.7 \mathrm{U} /$ day in patients receiving placebo (betweengroup difference $-0.3 \pm 5.7 \mathrm{U} /$ day, $p=0.956$ ).

Hypoglycaemia Figure 3 shows the frequency of confirmed (Fig. 3a) and severe (Fig. 3b) hypoglycaemia during 24week treatment. Both rates were significantly lower in the vildagliptin group (1.95 and 0 events per patient-year, respectively), than in the placebo group (2.96 and 0.10 events per patient-year, respectively; $p<0.001$ and $p=0.032$ based on $\chi^{2}$ test of two Poisson rates). Expressed in absolute number of events, 33 patients in the vildagliptin group reported a total of 113 events, none of which were severe (i.e. requiring assistance of another party). In the placebo group, 45 patients reported a total of 185 events, six of which were severe.

In the subgroup of patients aged $<65$ years, confirmed hypoglycaemia occurred at a rate of 3.11 events per patientyear in those receiving placebo vs 1.77 events per patient-
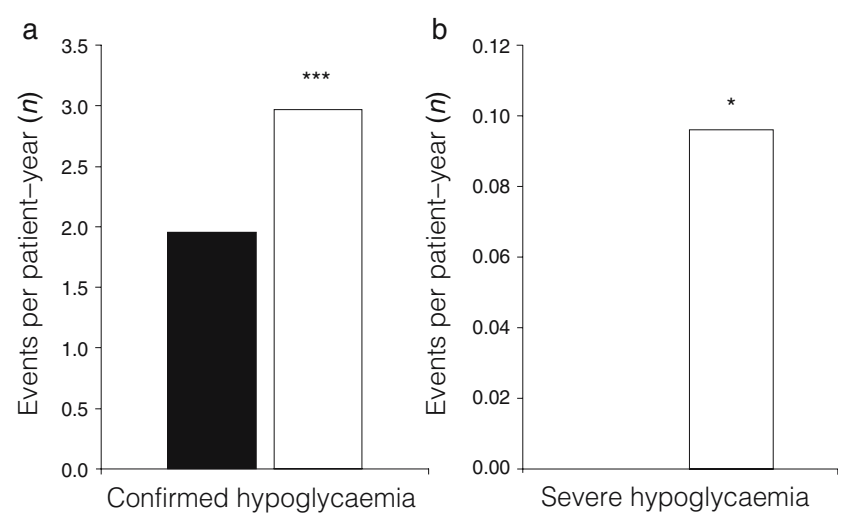

Fig. 3 Events per patient-year of confirmed hypoglycaemia (a) and severe hypoglycaemia (b) during 24-week treatment with vildagliptin (50 mg twice daily + insulin, $n=144$ ) (filled bars; value for severe hypoglycaemia $=0.00)$ or placebo $(+$ insulin; $n=152)$ (open bars). $* p<0.05, * * * p<0.001$ vs placebo

year in those receiving vildagliptin $(p<0.001)$. In the subgroup of patients aged $\geq 65$ years, the rate of confirmed hypoglycaemia was numerically lower in patients receiving vildagliptin (2.32 events per patient-year) than in those receiving placebo (2.64 events per patient-year), but this was not statistically significant. Of four patients in the whole cohort who experienced one or more severe events with placebo, two were $\geq 65$ years. One of these severe events, which occurred in a 69-year-old woman, was classified as life-threatening and required hospitalisation. An episode of severe hypoglycaemia in a 48 -year-old male patient receiving placebo led to loss of balance and a bone fracture.

Lipids and body weight Fasting lipid levels at baseline were similar in the two treatment groups. In the combined cohort at baseline, fasting triacylglycerol, total cholesterol, LDL, HDL, non-HDL and VLDL cholesterol averaged 1.8, 4.9, 2.7, 1.3, 3.5 and $0.8 \mathrm{mmol} / \mathrm{l}$, respectively. These changed by less than $4 \%$ from baseline in both treatment groups. However, relative to placebo, vildagliptin significantly decreased total cholesterol (between-group difference $-4.0 \pm 1.8 \%, p=0.026$ ), because total cholesterol decreased in vildagliptin-treated patients $(\mathrm{AM} \Delta-3.6 \pm 1.4 \%)$ and increased in patients receiving placebo (AM $\Delta 0.5 \pm 1.3 \%$ ). Similarly, relative to placebo, vildagliptin decreased LDL-cholesterol (between-group difference $-5.8 \pm 2.9 \%, p=0.048$ ) and non-HDL-cholesterol (between-group difference $-5.5 \pm 2.5 \%, p=0.026$ ). Vildagliptin had no statistically significant effect on fasting triacylglycerol, HDL-cholesterol or VLDL-cholesterol.

Body weight at baseline averaged $94.5 \pm 1.5 \mathrm{~kg}$ in patients randomised to vildagliptin and $95.1 \pm 1.7 \mathrm{~kg}$ in patients randomised to placebo. The $\mathrm{AM} \Delta$ body weight was $1.3 \pm 0.3 \mathrm{~kg}$ in patients receiving vildagliptin and $0.6 \pm$ $0.3 \mathrm{~kg}$ in patients receiving placebo. The between-group difference in the $\mathrm{AM} \Delta$ body weight at study endpoint $(0.7 \pm 0.4 \mathrm{~kg})$ was not statistically significant $(p=0.067)$. 
Tolerance When added to insulin therapy, the overall frequency of adverse events in patients receiving vildagliptin $(81.3 \%)$ was similar to that in patients receiving placebo $(82.9 \%)$. Other than confirmed hypoglycaemia (detailed above), the most commonly reported specific adverse events in patients receiving vildagliptin were: tremor (18.1\%), asthenia (16.7\%), hyperhidrosis (16.7\%), dizziness $(13.2 \%)$ and headache $(9.0 \%)$. In patients receiving placebo, the most frequent specific adverse events were tremor $(25.0 \%)$, hyperhidrosis $(23.0 \%)$, dizziness $(15.1 \%)$, asthenia $(13.2 \%)$ and upper respiratory tract infection (9.9\%). All other specific adverse events were reported by less than $10 \%$ of patients in either group and there were no remarkable differences between treatment groups in the incidence of any specific adverse event.

The percentage of patients reporting adverse events that were judged by the investigator to be possibly related to study medication was lower in the vildagliptin treatment group (28\%) than in the placebo group (36\%), largely due to hypoglycaemic events or related symptoms. Serious adverse events were experienced by a similar number of patients receiving vildagliptin (8.3\%) and placebo (9.2\%). The only specific serious adverse event reported by more than one patient was hypoglycaemia, reported by four patients receiving placebo $(2.6 \%)$ and by no vildagliptin-treated patients. More patients discontinued due to an adverse event (excluding death) in the vildagliptin group $(n=9,6.3 \%)$ than in the placebo group $(n=1,0.7 \%)$. Only single occurrences of adverse events leading to premature discontinuation were recorded. Discontinuations suspected to be related to study drug administration were one case of hypersensitivity (moderate exanthema of forearm with no associated symptoms) and one case of muscle spasm in the vildagliptin group, and one case of gastritis in the placebo group. All other discontinuations were considered by the local investigators to be not related to study drug. The reasons for these discontinuations (all in the vildagliptin group) were one instance each of abdominal wall mass, blood urea increased, dyspepsia, generalised oedema, Guillain-Barré syndrome, hallucination and shoulder pain. One patient in the vildagliptin group died from sepsis (as a post-surgical complication of gastric cancer). One patient in the placebo group died from coronary artery disease.

No major changes from baseline to endpoint or betweentreatment differences at endpoint were observed for any haematological, biochemical or urinalysis parameter, and no consistent trends over time were noted. No major changes from baseline to endpoint or between-treatment differences at endpoint were observed for any vital sign, and no consistent trends over time were noted. The frequency and nature of ECG changes from baseline to endpoint were comparable in the two treatment groups.

\section{Discussion}

The main finding of this 24-week, randomised, placebocontrolled trial was that, despite an improvement in glycaemic control in patients with type 2 diabetes that was poorly controlled with high doses of insulin, the addition of vildagliptin was associated with reduced hypoglycaemia, particularly severe hypoglycaemia.

The patients enrolled in the present study were on average obese and required $\sim 80 \mathrm{U} /$ day of insulin; they had a long history of disease ( $>14$ years) and also long duration of insulin treatment ( $>6$ years). These factors and the high prevalence of comorbid conditions can make treatment of diabetes difficult. In this population, vildagliptin (50 mg twice daily) decreased $\mathrm{HbA}_{1 \mathrm{c}}$ by $0.5 \%$ relative to baseline and $0.3 \%$ relative to placebo. The overall incidence of adverse events with vildagliptin was the same as that with placebo, and there was little weight gain and a modest improvement in some lipid parameters.

There are few studies of an oral agent added to insulin therapy in patients with comparable phenotype, thus direct comparisons are problematic [7]. In studies of patients most closely resembling the participants in the present study, it becomes apparent that somewhat greater efficacy may be achieved at the expense of undesirable side effects. For example, in a 6-month study comparing rosiglitazone ( 2 or $4 \mathrm{mg}$ daily) with placebo, rosiglitazone produced dose-related reductions in $\operatorname{HbA}_{1 \mathrm{c}}(\Delta-0.6$ and $-1.2 \%$, respectively), accompanied by dose-related increases in hypoglycaemia, oedema and weight gain [8]. In a 16-week study, metformin titrated to $2,550 \mathrm{mg}$ /day decreased $\mathrm{HbA}_{1 \mathrm{c}}$ by $0.6 \%$, but with a twofold increase in severe hypoglycaemia and a more than fourfold increase in gastrointestinal adverse events [9]. When data from seven disparate studies of a sulfonylurea added to insulin were pooled, it appeared that sulfonylurea reduced $\mathrm{HbA}_{1 \mathrm{c}}$ by $0.3 \%$ relative to placebo [7], similar to vildagliptin in the overall cohort. However, direct comparisons would be necessary to achieve a more complete understanding of the relative effectiveness and tolerability of different oral agents in combination with insulin.

Hypoglycaemia is a major limiting barrier to good glycaemic control with insulin [10]. Our finding of reduced hypoglycaemia with vildagliptin compared with placebo in the present study is therefore of interest [11]. There were approximately $40 \%$ fewer episodes of hypoglycaemia overall and, importantly, no severe hypoglycaemia in vildagliptin-treated patients, including in patients aged $\geq 65$ years, a group in which hypoglycaemia is of particular concern. The mechanism behind this reduced hypoglycaemia is unclear. Overall a very small, and not statistically significant increase in daily insulin dose was seen. In 
patients receiving placebo, this increase was slightly greater than in vildagliptin-treated patients (4.1 vs $1.2 \mathrm{U} /$ day). Although conceivable, it is unlikely that this contributed to the higher rate of hypoglycaemia in patients receiving placebo.

An intriguing hypothesis, which can be further addressed in mechanistic studies, is that DPP-4 inhibition restores pancreatic alpha cell function, improving the ability to sense and respond to changes in plasma glucose levels. As discussed in a recent review [12], the effects of glucagon-like peptide-1 do not appear to be limited to suppression of glucagon release in the presence of hyperglycaemia; rather, during hypoglycaemia, activation of the glucagon-like peptide-1 receptor (by agonists such as exenatide) increases glucagon levels, enhancing the stimulatory effect of low glucose levels on the alpha cell [13].

Although explored by subgroup analysis only, another interesting finding of the present study is that in patients aged $\geq 65$ years, vildagliptin decreased $\mathrm{HbA}_{1 \mathrm{c}}$ by $0.6 \%$ relative to placebo, while little change was seen in younger patients. There is no definitive explanation for this difference. However, vildagliptin has been shown to improve both beta cell [1, 14] and alpha cell function [2]. In the present study, such an improvement of beta cell function may make a lesser contribution to the efficacy of vildagliptin, due to chronic exposure of patients to high insulin levels of exogenous origin. Since elderly subjects have been reported to have significantly higher plasma glucagon levels than younger people [15], vildagliptin-mediated suppression of inappropriate glucagon secretion may contribute to the greater efficacy observed in elderly as compared with younger patients. In addition, older patients with type 2 diabetes tend to have a predominant postprandial hyperglycaemia [16], which is addressed by the robust effect of vildagliptin on postprandial hyperglycaemia [5].

Several limitations of our trial are worth noting. First, the study design allowed adjustments of insulin dose (for ethical reasons), which could have made interpretation difficult. However, insulin dose essentially did not change, again representing what often occurs in clinical practice. Second, the therapeutic approach represented by the current study may be considered uncommon in some countries. Third, there was no active comparator. However, placebo is the most appropriate comparator for assessment of safety-an important component of the present study.

In summary, vildagliptin (50 mg twice daily) added to insulin therapy in patients with type 2 diabetes improved glycaemic control, was well tolerated and was associated with a reduced incidence of hypoglycaemia relative to placebo.
Acknowledgements The authors gratefully acknowledge the investigators and staff at the 68 participating sites. We also acknowledge the editorial assistance of, and helpful discussions with, B. Dunning Lower, as well as helpful discussions with J. E. Foley. This study was funded by Novartis Pharmaceuticals Corporation. V. Fonseca was also supported in part by NIH grants from the Division of Research Resources, National Institutes of Health (grant numbers 5M01RR05096 and RR-00827) in support of the General Clinical Research Center.

Duality of interest This study was funded by Novartis Pharmaceuticals Corporation, the maker of vildagliptin. Five of the authors are employed by the company or one of its subsidiaries (see affiliations). A. Schweizer, M. A. Baron, I. Chang and S. Dejager are also shareholders. V. Fonseca has received other grants (to Tulane University) and honoraria from Novartis.

\section{References}

1. Mari A, Sallas WM, He YL et al (2005) Vildagliptin, a dipeptidyl peptidase-IV inhibitor, improves model-assessed $\beta$-cell function in patients with type 2 diabetes. J Clin Endocrinol Metab 90:4888-4894

2. Ahrén B, Landin-Olsson M, Jansson P-A et al (2004) Inhibition of dipeptidyl peptidase-4 reduces glycemia, sustains insulin levels and reduces glucagon levels in type 2 diabetes. J Clin Endocrinol Metab 89:2078-2084

3. Ristic S, Byiers S, Foley J, Holmes D (2005) Improved glycaemic control with dipeptidyl peptidase-4 inhibition in patients with type 2 diabetes: vildagliptin (LAF237) dose response. Diabetes Obes Metab 7:692-698

4. Pratley RE, Jauffret-Kamel S, Galbreath E, Holmes D (2006) Twelve-week monotherapy with the DPP-4 inhibitor vildagliptin improves glycemic control in subjects with type 2 diabetes. Horm Metab Res 38:423-428

5. Ahrén B, Gomis R, Standl E, Mills D, Schweizer A (2004) Twelve- and 52-week efficacy of the dipeptidyl peptidase IV inhibitor LAF237 in metformin-treated patients with type 2 diabetes. Diabetes Care 27:2874-2880

6. Meneilly GS, Elliott T, Tessier D, Hards L, Tildsesley H (1996) NIDDM in the elderly. Diabetes Care 19:1320-1325

7. Yki-Järvinen H (2001) Combination therapies with insulin in type 2 diabetes. Diabetes Care 24:758-767

8. Raskin P, Rendell M, Riddle MC et al (2001) A randomized trial of rosiglitazone therapy in patients with inadequately controlled insulin-treated type 2 diabetes. Diabetes Care 24: $1226-1232$

9. Wulffele MG, Kooy A, Lehert P et al (2002) Combination of insulin and metformin in the treatment of type 2 diabetes. Diabetes Care 25:2133-2140

10. Hepburn DA, MacLeod KM, Pell AC, Scougal IJ, Frier BM (1993) Frequency and symptoms of hypoglycaemia experienced by patients with type 2 diabetes treated with insulin. Diabet Med 10:231-237

11. American Diabetes Association Workgroup on Hypoglycemia (2005) Defining and reporting hypoglycemia in diabetes: a report from the American Diabetes Association. Diabetes Care 28:12451249

12. Dunning BE, Foley JE, Ahrén B (2005) Alpha cell function in health and disease: influence of glucagon-like peptide-1. Diabetologia 48:1700-1713 
13. Degn KB, Brock B, Juhl CB et al (2004) Effect of intravenous infusion of exenatide (synthetic exendin-4) on glucose-dependent insulin secretion and counterregulation during hypoglycemia. Diabetes 53:2397-2403

14. Ahrén B, Pacini G, Foley JE, Schweizer A (2005) Improved mealrelated beta-cell function and insulin sensitivity by the dipeptidyl peptidase-IV inhibitor vildagliptin in metformin-treated patients with type 2 diabetes over 1 year. Diabetes Care 28:1936-1940
15. Basu R, Breda E, Oberg AL et al (2003) Mechanisms of the ageassociated deterioration in glucose tolerance: contribution of alterations in insulin secretion, action, and clearance. Diabetes 52:1738-1748

16. Wahl PW, Savage PJ, Psaty BM et al (1998) Diabetes in older adults: comparison of 1997 American Diabetes Association classification of diabetes mellitus with 1985 WHO classification. Lancet 352:1012-1015 